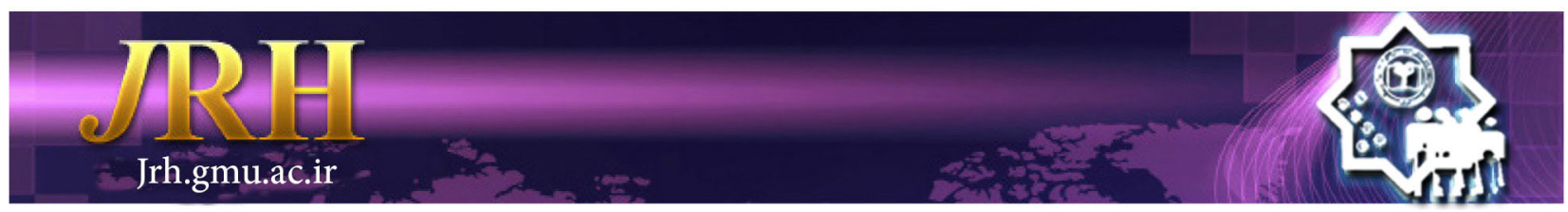

\title{
Using of health belief model on needlestick injuries and bloodborne pathogens among nurses
}

Mehrshad Sedigh ${ }^{1}$, Nader Zarinfar ${ }^{2}$, Mahboobeh Khorsandi ${ }^{3}$, Bahman Sadeghi Sadeh ${ }^{4}$

\author{
Journal of Research \& Health \\ Social Development \& Health Promotion \\ Research Center \\ Vol. 9, No.1, Jan \& Feb 2019 \\ Pages: 29- 36 \\ DOI: 10.29252/jrh.9.1.29 \\ Original Article
}

1. Graduated student of general practitioner degree, School of Medicine, Arak University of Medical Sciences, Arak, Iran

2. Correspondence to: Department of Infective Disease, School of Medicine, Arak University of Medical Sciences, Arak, Iran

Email: zarinfar@arakmu.ac.ir

3. Department of Health Education and Promotion, School of Health, Arak University of Medical Sciences, Arak, Iran

4. Department of Social Medicine, School of Medicine, Arak University of Medical Sciences, Arak, Iran

Received: 5 Apr 2015

Accepted: 12 Jul 2015

How to cite this article: Sedigh M, Zarinfar N, Khorsandi M, Sadeghi Sadeh B. Using of health belief model on needlestick injuries and bloodborne pathogens among nurses. $J$ Research \& Health2019; 9(1): 29- 36

\begin{abstract}
Needle Stick Injury (NSI) is one of the spread abroad and dangerous risks in nurse job that HIV, $\mathrm{HCV}$ and $\mathrm{HBV}$ are the most common infection which were transferred by blood. The aim of this study was evaluation of the education effect basis of the health belief model of knowledge and behavioral prevention of NSI. This study was a quasi-experimental that 165 nurses were selected incidentally from the hospitals they has been organized into experimental and control group. Data were collected with health belief model questionnaire and checklist before and after intervention and also for control group executive working environment was used according to universal precautions. Results showed that the mean score of knowledge and components of health belief model increased in the control group meaningfully and perceived barrier didn't decrease meaningfully. Behaviors' scores increased and NSI decreased. Education program based on health belief model increased knowledge and most of health belief model constructs score and also improving prevention behavior and lead to decrease NSI.
\end{abstract}

Keywords: Health Belief Model, Needle Stick Injury, Nurses

\section{Introduction}

Occupational exposure is one of the most potential career risks personal healthcare worker $(\mathrm{HCW})$ and the most common and dangerous occupational exposure is caused by Needle Stick Injury (NSI)/ Sharps Injury (SI) [1,2]. Needle Stick/sharp objects injuries are the most important cause of deadly blood infections in healthcare workers [3-7] because they can transmit more than 20 pathogens to human, among which Human immunodeficiency virus (HIV), hepatitis $\mathrm{C}$ virus (HCV), and hepatitis $\mathrm{B}$ virus (HBV) are more likely to transmit [8-10]. The world health organization has announced in 2005 that out of 35 million healthcare workers around the world, 3 million are exposed to blood pathogens every year through these injuries among whom there are 2 million, 0.9 million, and 0.17 million people exposed to $\mathrm{HBV}, \mathrm{HCV}$, and HIV, respectively. These injuries cause 15,000 cases of HCV, 70000 cases of HBV, and 500 cases of HIV $[11,12]$ such that hepatitis B, C, and HIV are accounted for $37 \%, 39 \%$, and $4.4 \%$ of these infections, respectively [11]. The risk of transmission of three viral diseases, HBV, HCV, and HIV, after once needlestick/sharp injury, is $6-30 \%, 1.8 \%$, and $0.3 \%$, respectively [13]. Studies all over the world showed that nurses 
are at the highest risk among healthcare workers. [5,14-18]. Unfortunately, nurses have a low level of knowledge about the injuries caused by needlestick/sharp objects. The research performed in Pakistan by Naveed Zjunj et al. indicated the low level of knowledge in healthcare workers about the transmission of these diseases by needlestick/ sharp objects [19]. It has been estimated that annually $600000-800000$ injuries occur due to needle stick sinking in healthcare workers where almost 70\% are not reported [19-21]. Tabak et al. have shown that there is a direct relationship between perceived severity of diseases caused by needlestick/sharp objects injuries and trusting the effectiveness of the report and the motivation to stay in good health, in one hand, and reporting the injuries caused by needlestick/ sharp objects, on the other hand [22].

Yang et al. reported a 50.1\% injury risk by sharp objects accounting for 8 times per person in a year. This figure is 7.3 in nurses who had been trained and 11.7 in nurses with less training [23]. In the performed studies, education could affect the knowledge and behaviors of people and reduced the injuries of needle-stick/ sharp objects [23-27].

The health belief model is one of the health education models that examine effective factors in health behaviors, particularly preventive behaviors in people. In this model, it is believed that people adopt preventive behaviors against diseases only if they perceive they are at risk of the disease and believe in the usefulness of the preventive behaviors. On the other hand, perceived barriers to doing such behavior should be decreased [28].

According to the importance of informing nurses about the preventive behaviors against injuries caused by needle-stick/ sharp objects and the fact that the health belief model can be effective in explaining the preventive behavior against injuries caused by needlestick/ sharp objects and since these injuries are accompanied with irrecoverable complications, therefore conducting studies on this issue has great importance. The nurses are considered as a high-risk group due to direct contact with blood and secretions; so far, there has been no research on the effect of education based on the health belief model on the behaviors and knowledge of this group in order to prevent injuries caused by needle-stick/ sharp objects in the Iran, particularly in Arak city. The aim of this research was to investigate the effect of education on the preventive behaviors against injuries caused by needle-stick and transmitted diseases based on health belief model among nursing staff in Arak university of medical sciences 2013.

\section{Method}

In this quasi-experimental study a group of 82 participants (male: 12, female: 70) was selected randomly among nurses in Arak hospitals. At the same time, 84 nurses (male: 14, female: 70) were randomly selected from the same centers as the control group. In the case group, a training program was held for three hours with the attendance of professors and hospital supervisors. 83 participants participated in this program including nurses, midwives, and doctors. In designing the educational content based on the guideline of American Center for Disease Control and Prevention and universal precaution $[29,30]$, the components of the health belief model including perceived threat, perceived sensitivity, perceived severity, perceived benefits, and perceived barriers, as well as self-efficacy and cues to action, were considered. In order to provide a better presentation, educational pamphlets were given to nurses. In order to sensitize participants at the beginning of the presentation, some real cases of nurses infected by HCV and HBV, and HIV due to occupational exposure were presented and discussed. Then, the audience was provided with several facts and agreements in Iran, the province of Markazi, and the Arak city. Next, the preventing principles of needle stick and of infections caused by needle stick and vaccination effect were explained [30]. Three months after the end of the workshop, the effectiveness of the intervention was studied by a questionnaire which was designed by experts to examine nurses' knowledge, attitude, and behaviors in the case and control groups. 
The behavior of both control and intervention groups in this questionnaire was evaluated by the WHO standard checklist. Finally, the data collected from 82 nurses in the experimental group and 84 nurses in the control group were analyzed by SPSS-16. The one-sample kolmogorov-smirnov test, independent t-test and paired sample t-test were also used significant level $(<0.05)$. This study was approved by the ethics Committee of Arak university of medical sciences (Code 90-122-7). Informed consent was obtained before performing the study and the participants were allowed to leave the study freely. The data gathering tool was designed based on the components of health belief model and educational objectives. In this questionnaire, 52 questions were designed to assess the levels of knowledge, perceived benefits and barriers, sensitivity, severity, and self-efficacy. Its content and construct validity were confirmed by referring to the opinion of professors, consultants, relevant experts, and infectious diseases specialists. Furthermore, its validity and reliability were determined by Cronbach's alpha after implementing on a limited number of available nurses. 82 nurses who participated in the workshop responded to the questions before and after the meeting. In addition, some behavioral variables such as participation in similar workshops, vaccination, collaboration with infection control nurses, and a history of injuries caused by needle stick were asked.

\section{Results}

There was no significant difference between the two groups in terms of career, educational centers, marital status, gender, history of participation in the workshop, age, and service record ( $p>0.05)$.

The primary analysis showed that there was no significant difference between the case and control groups in terms of the structures of health belief model and preventive behaviors against needle stick injuries before training $(\mathrm{p}>0.05)$.

The changes in the control group are presented in Table 1 before and after performing the educational intervention.

Table 1 The mean score of knowledge and attitude of the control group before intervention and 3 months later

\begin{tabular}{|c|c|c|c|c|c|}
\hline & & $\mathrm{N}$ & Mean & $\begin{array}{l}\text { Standard } \\
\text { deviation }\end{array}$ & p-value \\
\hline \multirow{2}{*}{ Knowledge } & Before performing the program & 83 & 5.90 & 1.52 & \multirow{2}{*}{0.13} \\
\hline & 3 months later & 83 & 6.14 & 1.37 & \\
\hline \multirow{2}{*}{$\begin{array}{l}\text { Perceived } \\
\text { benefits }\end{array}$} & Before performing the program & 83 & 14.48 & 3.30 & \multirow{2}{*}{0.249} \\
\hline & 3 months later & 83 & 14.93 & 3.36 & \\
\hline \multirow{2}{*}{$\begin{array}{l}\text { Perceived } \\
\text { barriers }\end{array}$} & Before performing the program & 83 & 34 & 5.89 & \multirow{2}{*}{0.678} \\
\hline & 3 months later & 83 & 33.75 & 5.56 & \\
\hline \multirow{2}{*}{$\begin{array}{l}\text { Perceived } \\
\text { sensitivity }\end{array}$} & Before performing the program & 83 & 14.20 & 2.16 & \multirow{2}{*}{0.416} \\
\hline & 3 months later & 83 & 14.40 & 1.91 & \\
\hline \multirow{2}{*}{$\begin{array}{l}\text { Perceived } \\
\text { severity }\end{array}$} & Before performing the program & 83 & 8.03 & 1.76 & \multirow{2}{*}{0.760} \\
\hline & 3 months later & 83 & 8.1 & 1.78 & \\
\hline \multirow{2}{*}{ Self-efficacy } & Before performing the program & 82 & 1.29 & 1.13 & \multirow{2}{*}{0.784} \\
\hline & 3 months later & 82 & 1.243 & 1.128 & \\
\hline \multirow{2}{*}{ Cues to action } & Before performing the program & 82 & 2.048 & 1.076 & \multirow{2}{*}{0.943} \\
\hline & 3 months later & 82 & 2.036 & 1.070 & \\
\hline \multirow{2}{*}{ Behavior } & Before performing the program & 79 & 12.783 & 2.681 & \multirow{2}{*}{0.450} \\
\hline & 3 months later & 79 & 13.151 & 2.567 & \\
\hline
\end{tabular}

Table 2 shows a comparison of the structures of health belief model in the case group before and after the educational intervention based on the given model. There was a significant difference in all the structures of the health belief model compared to the pre-training step, with the exception of perceived barriers. 
Table 2 Comparison of the mean score of knowledge and attitude in terms of timescales in the intervention group

\begin{tabular}{|c|c|c|c|c|c|}
\hline & & $\mathrm{N}$ & Mean & $\begin{array}{l}\text { Standard } \\
\text { deviation }\end{array}$ & p-value \\
\hline \multirow{3}{*}{ Knowledge } & Pretest & 83 & 6.277 & 1.318 & \multirow{3}{*}{0.001} \\
\hline & Posttest & 83 & 8.421 & 0.682 & \\
\hline & Posttest; 3 months later & 83 & 8.313 & 1.360 & \\
\hline \multirow{3}{*}{$\begin{array}{l}\text { Perceived } \\
\text { benefits }\end{array}$} & Pretest & 83 & 14.614 & 3.157 & \multirow{3}{*}{0.001} \\
\hline & Posttest & 83 & 17.819 & 1.788 & \\
\hline & Posttest; 3 months later & 83 & 18.433 & 1.970 & \\
\hline \multirow{3}{*}{$\begin{array}{l}\text { Perceived } \\
\text { barriers }\end{array}$} & Pretest & 83 & 33.915 & 6.589 & \multirow{3}{*}{0.076} \\
\hline & Posttest & 83 & 32.469 & 2.927 & \\
\hline & Posttest; 3 months later & 83 & 32.602 & 2.836 & \\
\hline \multirow{3}{*}{$\begin{array}{l}\text { Perceived } \\
\text { sensitivity }\end{array}$} & Pretest & 83 & 14.494 & 2.339 & \multirow{3}{*}{0.001} \\
\hline & Posttest & 83 & 15.988 & 2.222 & \\
\hline & Posttest; 3 months later & 83 & 18.578 & 1.397 & \\
\hline \multirow{3}{*}{$\begin{array}{l}\text { Perceived } \\
\text { severity }\end{array}$} & Pretest & 83 & 8.024 & 1.731 & \multirow{3}{*}{0.001} \\
\hline & Posttest & 83 & 8.915 & 1.507 & \\
\hline & Posttest; 3 months later & 83 & 10.228 & 0.954 & \\
\hline \multirow{3}{*}{ Self-efficacy } & Pretest & 83 & 1.241 & 1.132 & \multirow{3}{*}{0.001} \\
\hline & Posttest & 83 & 2.036 & 1.162 & \\
\hline & Posttest 3 months later & 83 & 2.481 & 721. & \\
\hline \multirow{3}{*}{$\begin{array}{l}\text { Cues to } \\
\text { action }\end{array}$} & Pretest & 83 & 1.988 & 1.087 & \multirow{3}{*}{0.001} \\
\hline & Posttest & 83 & 2.469 & .860 & \\
\hline & Posttest 3 months later & 83 & 2.662 & 0.590 & \\
\hline
\end{tabular}

Considering changes in behavior and performance were of the goals of this research, only behavior changes were analyzed before

intervention and 3 months later in the paired groups by t-test. The statistical results are presented in Table 3.

Table 3 Comparison of the mean score before intervention and 3 months later

\begin{tabular}{lcccc}
\hline & $\mathrm{N}$ & Mean & $\begin{array}{r}\text { Standard } \\
\text { deviation }\end{array}$ & p-value \\
\hline Pretest behavior & 80 & 12.600 & 2.670 & \multirow{2}{*}{0.001} \\
Behavior 3 months later & 80 & 14.625 & 2.567 & \\
\hline
\end{tabular}

Finally, in order to determine the effect of an educational intervention based on the health belief model in its different areas, the mean score obtained in the control group 3 months later and that of the intervention group 3 months later were compared using t-test of independent groups. The results are shown in Table 4.

Table 4 Comparison of the mean score of behavior in the control and intervention groups 3 months after the intervention

\begin{tabular}{lllcc}
\hline & $\mathrm{N}$ & Mean & Standard deviation & P value \\
\hline Behavior of the intervention group 3 months later & 83 & 14.71 & 2.57 & 0.0001 \\
\hline
\end{tabular}

\section{Discussion}

This study examined the effect of education based on health belief model on nurses' attitude and behaviors in preventing needle-stick and sharp objects injuries and transmitted diseases. This study was a quasi-experimental consisting of experimental group (82 nurses) 
and control group (84 nurses) who were matched according to age, gender, occupation, hospital, and place of work, marital status, and similar workshop background. Also, the variables of knowledge and perceived benefits, perceived barriers, perceived sensitivity, perceived severity, perceived self-efficacy, and cues to action as well as the performance of nurses were investigated based on health belief model in this group in various time intervals.

The first part of the research studied the extent of knowledge. There was no significant difference between the intervention group and control group before the intervention in terms of nurses knowledge ( $p>0.05)$. In addition, there was a meaningful increase between pretest to posttest in the intervention group $(p<0.001)$. The increase was still meaningful after 3 months in spite of a slight decrease $(p<0.0001)$. There was also a significant difference between the intervention group and control group after 3 months $(p<0.0001)$. The posttest extent of knowledge decreased 3 months after the intervention, which represents the necessity of the training iteration. The primary knowledge of nurses in the intervention and control groups was consistent with the knowledge level of healthcare staff in Kabiri's research in Iran as well as in Johnjuo's research, which has reported the results based on the health belief model [31]. However, this value may increase due to country progress and application of universal precaution (19.31) so that the nurses' knowledge level has been reported extremely high in the research performed in Jamaica by Vaz [24].

In a study conducted by Harshal in India on 108 nursing students, the knowledge level significantly increased after conducting a training course in three areas, general information about HIV, preventing injuries caused by needle stick, and prevention of AIDS [25].

In similar studies in China by Wany et al., the universal precaution training course could increase the nurses' knowledge even after 4 months meaningfully ( $p<0.0001)$.

In addition, in an individual study in China by Huang, the increase in knowledge due to a training course was confirmed [26]; therefore, all of these studies are consistent with the present study. The mean score of the perceived benefits in the posttest had a significant increase in the intervention group compared to the pretest score, which indicated the increased perceived benefits even after the intervention. In addition, there was a significant difference between the control and intervention groups in the posttest 3 months later.

In Efstathiou research and Rahmati research, they mainly focused on increasing the perceived benefits after the intervention, which is consistent with the present research $[32,33]$. In the perceived barriers domain, there was no significant difference between the mean scores of the intervention and control groups. The mean score of perceived barriers decreased in the posttest compared to pretest, although it was not significant and it increased in 3-months posttest. However, its score was still fewer than the posttest score and there was no significant difference between the intervention and control groups in 3-months posttest.

In a research performed by Efstathiou, training could be effective in the level of people's perceived barriers that remained constant after 2 months where the lack of time and time-consuming cautions were considered as some of these barriers.

In addition, in research of Efstathiou et al, it was shown that implementing the continuous training programs and repeated reminding of standard precautions have a better effect [32]. There was no significant difference in perceived sensitivity before training between the intervention and control groups; however, there was a significant increase in the mean score in the posttest. In addition, there was a significant difference in the mean score of perceived sensitivity between the intervention and control groups 2 months later.

According to the findings of this study regarding the perceived severity level, there was no significant difference in the mean score between the intervention and control groups and the mean score of perceived severity had a significant increase in the intervention 
group after the test where this increase remained at the posttest 3 months later and there was a statistically significant difference between the control and intervention groups after 3 months. One of the reasons for using the health belief model for needlestick injuries and the transmitted diseases was to prevent deadly consequences that could be useful in adopting preventive behaviors. In Efstathiou study, nurses' perceived severity increased after intervention [32]. In the Shigemi's study, perceived severity had the highest effect on adopting preventive behaviors [34]. Based on the health belief model, high level of perceived sensitivity is necessary to promote the motivation of individuals in adopting preventive health behaviors that must be focused on the training program. In Efstathiou's study about perceived sensitivity, there was no significant difference between intervention and control groups in terms of self-efficacy before training; the mean score had a significant increase in the posttest compared to pretest where the increase could be seen in the posttest 3 months later. In addition, there was a significant difference in the mean score of self-efficacy between the intervention and control groups in the posttest 3 months later.

In Efstathiou study on nurses, it was shown that in spite of less initial self-efficacy, it increased after intervention [32].

In the domain of cues to action, which is the last part of the health belief model, there was no significant difference between the intervention and control groups before the intervention. The mean score of the posttest increased in the intervention group. This increase was observed in the score of posttest 3 months later. In addition, there was a significant difference in the mean score of cues to action in the intervention group in the posttest 3 months later.

The Efstathiou's study showed that the level of preventive cues to action increased in nurses [32]. In studying the effect of workshop training on the behavior based on the health belief model, the research findings showed that there was no significant difference in the behavior score between theintervention and control groups before intervention and the mean score increased in the posttest 3 months later compared to pretest, which demonstrates the effect of training on behavior based on the health belief model. In addition, there was a significant difference between the control and intervention groups in the posttest 3 months later.

In the studies performed by Huang, there was a significant increase in the nurses' behavior score 4 months after the intervention; however, no change was made in using the gloves [26].

In the Wang's study, the behaviors of nursing students improved by the performed intervention [24]. Furthermore, in the Yang study in Taiwan, training not only led to increased reporting but also decreased the extent of needle stick injuries [23].

The reporting percentage varied from $20.7 \%$ to $71.4 \%$ where this increase was considerable due to promoting attitude based on the health belief model; thus, this finding is consistent with the Yang's finding [23].

Due to the limited presence of the intervention group in the training program, the duration of intervention was short.

It is suggested that use of virtual teaching methods and comparison with face-to-face approach

\section{Conclusion}

In the present study, after the educational intervention based on the health belief model, the results indicated that the workshop training had a positive effect on the knowledge, perceived sensitivity, severity, benefits, cues to action, and preventive behaviors regarding needle stick and sharp objects injuries and diseased disease transmitted by the injuries. Therefore, it is recommended to apply this model in healthcare centers, hospitals, and clinics of the Arak city.

\section{Acknowledgements}

Would like to express my special thanks to all nurses who take part in our research. Would also like to thank vice chancellor's office of research \& technology affairs in 
Arak university of medical sciences. This study was approved by the ethics committee of Arak university of medical sciences (Code 90-122-7).

\section{Contribution}

Study design: NZ, MK, MS

Data collection and analysis: MS, BSS

Manuscript preparation: NZ, MK, MS, BSS

\section{Conflict of Interest}

"The authors declare that they have no competing interests."

\section{Funding}

This study is a part of a General Physician and funded by research deputy of arak university of medical sciences (grant number=1368). The authors would like to thank the research deputy of arak university of medical sciences for its financial support

\section{Refrences}

1- Thomas WJ, Murray JR. The incidence and reporting rates of needle-stick injury amongst UK surgeons. Ann $R$ Coll Surg Engl2009; 91(1): 12-7.

2- Centers for disease control and prevention. National Institute for occupational safety and health (NIOSH) NIOSH Alert.2000; Preventing Needlestick Injuries in Health Care Settings, 1999. Publication No. 2000-108. Available at URL:www.cdc.gov/niosh/2000-108.html. Accessed Feb 16, 2013.

3- Cooley C, Gabriel J. Reducing the risks of sharps injuries in health professionals. Nurs Times2004; 100(26): 28-9.

4- Nasiri E, Mortazavi Y, Siamian H, Shabankhani B. The prevalence and study of the rate of needlestick injuries infected by blood in staff of special departments of teaching and non teaching hospital of Mazandaran province in 2003-2004. Iranian Journal of Infectious Diseases and Tropical Medicine2005; 10(29): 41-46.

5- Niosh Alert. Preventing needlestick injuries in health care settings.NIOSH; 2000. Avialable at URL: https:// www.cdc.gov/niosh/docs/2000-108/pdfs/2000-108.pdf. Accessed Feb 16, 2013.

6- Heptonstall J, Turnbull S, Henderson D, Morgan D, Harling K, Scott G. Sharps injury! A review of controversial areas in the management of sharps accidents. J Hosp Infect 1999; 43(1): 219-23.

7- Gerberding JL. Management of occupational exposures to blood-borne viruses. N Engl J Med1995;
332(7): 444-51.

8- Zanni GR, Wick JY. Preventing needlestick injuries. Consult Pharm2007; 22(5): 400-9.

9- Schmid K, Schwager C, Drexler H. Needlestick injuries and other occupational exposures to body fluids amongst employees and medical students of a German university: incidence and follow-up. J Hosp Infect2007; 65(2): 124-30.

10- Bryant. Organized systems of care. Am J Infect Control1997;25(5):363-4.

11- Prüss-Üstün A, Rapiti E, Hutin Y. Estimation of the Global Burden of Disease attributable to Contaminated Sharps Injuries Among Health-Care Workers. Am J Ind Med2005; 48(6): 482-90.

12- World health organization. Aide-memoire for a strategy to protect health workers from infection with blood borne viruses .2003; Geneva, Switzerland: WHO, November 2003 . Aviable at http://apps.who.int/iris/ bitstream/handle/10665/68354/WHO_BCT_03.11. pdf. Accessed Feb 16, 2013.

13- Exposure to blood what healthcare personnel need to know. 2003. Available at: https://www.cdc.gov/HAI/ pdfs/bbp/Exp_to_Blood.pdf. Accessed Feb 17, 2013 14- Fisman DN, Harris AD, Rubin M, Sorock GS, Mittleman MA. Fatigue increases the risk of injury from sharp devices in medical trainees: results from a casecrossover study. Infect Control Hosp Epidemiol2007; 28(1): 10-7.

15- Trim JC, Elliott TS. A review of sharps injuries and preventative strategies. J Hosp Infect2003; 53(4): 237-42. 16- Shiao J, Guo L, Mclawas Ml. Estimation of the risk of bloodborne pathogens to health care workers after a needlestick injury in Taiwan. Am J Infect Control2002; 30(1): 15-20.

17- Baghcheghi N, Koohestani HR, Rezaei K, Seraji A, Abedi AR. Prevalence needlestick/sharps injuries among nursing student and related factor. Iran Occupational Health Journal2011; 7(4): 32-39.

18- Azadi A, Anousheh M. Needlestick injuries reporting among clinical nurses. Iran Journal of Nursing2007; 20(49): 7-14.

19- Janjua NZ, Razaq M, Chandir S, Rozi S, Mahmood

B. Poor knowledge--predictor of nonadherence to universal precautions for blood borne pathogens at first level care facilities in Pakistan. BMC Infect Dis2007; 7(1): 81.

20- Siddique Kh, Anil Sh, Shoaib SF, Anwar I, Zafar A. Knowledge attitude and practices regarding needle stick injuries amongst healthcare providers. Pakistan Journal of Surgery2008; 24(4): 243-8.

21- Nejadrahim R, Gharahughi N, Sistanizade M. Needlestick injuries in the health care workers of Urmia educational hospitals. Journal of Urmia Nursing And Midwifery Faculty2005; 3(2): 69-77. 
22- Tabak N, Shiaabana AM, Shasha S. The health beliefs of hospital staff and the reporting of needlestick injury. J Clin Nurs2006; 15(10): 1228-39.

23- Yang YH, Liou SH, Chen CJ, et al. The effectiveness of a training program on reducing needlestick injuries/ sharp object injuries among soon graduate vocational nursing school students in southern Taiwan. J Occup Health2007; 49(5): 424-9.

24- Wang H, Fennie K, He G, Burgess J, Williams AB. A training programme for prevention of occupational exposure to bloodborne pathogens: impact on knowledge, behaviour and incidence of needle stick injuries among student nurses in Changsha, People's Republic of China. $J$ Adv Nurs2003; 41(2): 187-94.

25- Sabane HH, Dixit RR, Durge P. Impact of knowledge about Post exposure prophylaxis among nursing students-A cross sectional study. Healthline2011; 2(1): 27-31.

26- Huang J, Jiang D, Wang X, Liu Y, Fennie K, Burgess J, Williams AB. Changing knowledge, behavior, and practice related to universal precautions among hospital nurses in China. The Journal of Continuing Education in Nursing2002; 33(5): 217-24.

27- Petrucci C, Alvaro R, Cicolini G, Cerone MP, Lancia

L. Percutaneous and mucocutaneous exposures in nursing students: an Italian observational study. J Nurs Scholarsh2009; 41(4): 337-43.

28- Janz NK, Becker MH. The health belief model: a decade later. Health Educ Q1984; 11(1): 1-47.

29- World health organization. Post-exposure prophylaxis to prevent HIV infection. joint WHO/ILO guidelines on post-exposure prophylaxis (PEP) to prevent HIV infection. 2005, Available at : URL:http:// www. who. int/ hiv/ pub/ guidelines/ PEP/en/ng. Accessed Feb 21, 2013.

30- Vaz K, McGrowder D, Alexander-Lindo R, Gordon L, Brown P, Irving R. Knowledge, awareness and compliance with universal precautions among health care workers at the university hospital of the west Indies, Jamaica. Int J Occup Environ Med2010; 1(4): 171-81.

31- Kabir A, Tabatabaei SV, Khaleghi S, et al. Knowledge, attitudes and practice of Iranian medical specialists regarding hepatitis $\mathrm{B}$ and C. Hepat Mon2010; 10(3): 176-82.

32- Efstathiou G, Papastavrou E, Raftopoulos V, Merkouris A. Factors influencing nurses' compliance with Standard Precautions in order to avoid occupational exposure to microorganisms: A focus group study. BMC Nurs2011; 10: 1-10.

33- Rahmati Najarkolaei F, Niknami Sh, Amin Shokravi F, Ahmadi F, Jafari MR, Rahnama P. The implication of health belief model in planning educational programmes for preventing HIV/AIDS among university students. Payesh Journal2009; 8(4): 349-59.

34- Iriyama S, Nakahara S, Jimba M, Ichikawa M, Wakai S. AIDS health beliefs and intention for sexual abstinence among male adolescent students in Kathmandu, Nepal: a test of perceived severity and susceptibility. Public Health2007; 121(1): 64-72.

Copyright(C) 2016 ASP Ins. This open-access article is published under the terms of the Creative Commons Attribution-NonCommercial 4.0 International License which permits Share (copy and redistribute the material in any medium or format) and Adapt (remix, transform, and build upon the material) under the Attribution-NonCommercial terms. 